\title{
INTERAÇÃO E TRABALHO DOCENTE EM AULA DE ALFABETIZAÇÃO
}

\author{
INTERACTION AND TEACHER'S WORK \\ IN THE LITERACY CLASS
}

\section{Sandoval Nonato Gomes-Santos* Heloisa Gonçalves Jordão}

\section{RESUMO}

A interação em sala de aula é objeto de investigação em diferentes investimentos de pesquisa no campo dos estudos da linguagem. Para os estudos em Linguística Aplicada, entre os desafios da abordagem do tema encontra-se, conforme percepção de Kleiman (1991), a compreensão das relações entre a interação em sala de aula e problemas relativos ao processo de ensino e aprendizagem. Com base nessa percepção, este estudo propõe descrever e analisar a interação em uma sala de aula de alfabetização, a fim de investigar a articulação entre sua materialidade discursiva e seu funcionamento didático (GOMES-SANTOS, ALMEIDA, 2009; MATÊNCIO, 2001; ROJO, 2007). Do ponto de vista teórico, esse propósito é delimitado pela contribuição tanto de estudos sobre o problema da interação em sala de aula (MEHAN, 1979), quanto daqueles ocupados, particularmente, com a natureza didática dessa interação e com o lugar do trabalho docente em sua configuração (SCHNEUWLY, 2009). A geração dos dados consistiu de acompanhamento de uma turma de segundo ano do Ensino Fundamental de uma escola pública da rede de ensino de Taboão da Serra, município da região metropolitana de São Paulo (SP), cujas aulas foram objeto de registro em áudio e vídeo e em caderno de campo, durante o primeiro semestre escolar de 2011. Neste estudo, é considerada uma amostragem do corpus correspondente a um determinado dia de trabalho da alfabetizadora. A descrição e análise dos dados aponta para a relação de interdependência das atividades escolares propostas, dos objetos de ensino visados e dos instrumentos didáticos utilizados na sala de aula: as formas pelas quais esses elementos são combinados têm efeitos no formato da interação entre professora e alunos e desvelam alguns dos desafios presentes no cotidiano do trabalho de alfabetizar.

Palavras-chave: alfabetização; interação; trabalho docente.

\section{ABSTRACT}

Interaction in the classroom is an object of investigation in different research investments in the field of language studies. For studies in Applied Linguistics, among the challenges of the approach of the topic is found, as perceived Kleiman (1991), the understanding of the relationships between interaction in classroom and problems related to the teaching and

\footnotetext{
* USP, São Paulo (SP), Brasil. sandovalnonato@usp.br; USP, São Paulo (SP), Brasil. heloisa.jordao@ gmail.com
} 
learning process. Based on this perception, this study aims to describe and analyze the interaction in classroom literacy, in order to investigate the relationship between the discursive materiality and its didactic functioning (GOMES-SANTOS; ALMEIDA, 2009; MATÊN$\mathrm{CIO}, 2001$; ROJO, 2007). From the theoretical point of view, this purpose is defined by the contribution both from studies on the problem of interaction in the classroom (MEHAN, 1979), as those occupied particularly the didactic nature of this interaction and the place of teacher's work in its configuration (SCHNEUWLY, 2009). The data generated consisted of monitoring a second year Elementary Class of a public school in Taboão da Serra, metropolitan area of São Paulo (SP), whose classes were the object of record audio and video, and field notes during the first scholar term of 2011. In this study, only a sampling of the corpus, corresponding to a teacher workday of literacy, is contemplated. The description and analysis of the data points to the interdependence of school activities proposed, the objects of targeted education and teaching tools used in the classroom: the ways in which these elements are combined can have effects on the interaction between teacher and students and unveil some of the challenges present in the daily work of literacy.

Keywords: interaction; literacy; teacher's work.

\section{INTRODUÇÃO}

A interação em sala de aula é objeto de investigação em diferentes investimentos de pesquisa no campo dos estudos da linguagem. Particularmente no percurso dos estudos em Linguística Aplicada, o interesse por esse objeto configura-se, por exemplo, na compilação de artigos publicados no volume 18 de Trabalbos em Linguística Aplicada sob o título Interações Assimétricas, em 1991. No prefácio ao volume, Ângela Kleiman afirma que é especialmente interessante para a Linguística Aplicada a incorporação da ideia de interação. A autora salienta que, ao tomar como objeto de estudo "a interação como o meio em que se dá a aprendizagem", o linguista aplicado tem em sua frente aspectos da linguagem, da psicologia e da estrutura social integrados em um mesmo evento, e a consideração desses três aspectos é fundamental para descrever e explicar o funcionamento da sala de aula (KLEIMAN, 1991, p. 8). Encerra chamando a atenção para o desenvolvimento da área no Brasil e espera que a publicação auxilie e incentive novos pesquisadores que buscam respostas às questões de ensino e aprendizagem.

A percepção da autora sobre a relação de constituição recíproca entre a interação em sala de aula e os processos de ensino e aprendizagem está entre os desafios teóricos suscetíveis de adensar o conhecimento sobre a sala de aula, como assinalam vários estudos que se ocuparam do tema, entre os quais Gomes-Santos; Almeida (2009), Matêncio (2001) e Rojo (2007). Na esteira dessa percepção, este estudo propõe descrever e analisar a interação em uma sala de aula de alfabetização, a fim 
de investigar a articulação entre sua materialidade discursiva ${ }^{1}$ e seu funcionamento didático. Duas opções complementares delimitam esse objetivo.

A primeira refere-se ao foco no trabalho docente como recurso para compreender como essa articulação se constitui, o que implica, por sua vez, um duplo pressuposto: por um lado, o pressuposto de que a interação em sala de aula incorpora-se a um dado projeto didático implementado pelo trabalho docente no qual são previstos determinados objetivos e expectativas de aprendizagem, conteúdos ou objetos de ensino, além de dispositivos de distribuição e apropriação desses conteúdos. Por outro lado e complementarmente, o pressuposto de que todo projeto didático e o trabalho docente que o implementa são suscetíveis de reconfiguração quando submetidos ao calor da interação, na qual efetivamente ganham corpo.

A segunda opção diz respeito ao contexto particular em que se constituiu o trabalho docente objeto de descrição e análise: a sala de aula de alfabetização, lócus em que se opera comumente o ingresso institucional da criança não apenas no mundo da escrita, como também nos rituais e nas práticas do mundo da escola. Mais especificamente, trata-se de uma turma de segundo ano do Ensino Fundamental de uma escola pública da rede de ensino de Taboão da Serra, município da região metropolitana de São Paulo (SP), cujas aulas foram objeto de acompanhamento e registro em áudio e vídeo e em caderno de campo, durante o primeiro semestre escolar de 2011. Neste estudo, é considerada uma amostragem do corpus gerado correspondente ao ensino de língua portuguesa em um determinado dia de trabalho da alfabetizadora.

Considerando essa dupla opção, este estudo busca constituir-se em uma contribuição ao conjunto de descrições e análises da sala de aula da escola brasileira desenvolvido na pesquisa acadêmica do país. É ao interesse de adensamento da reflexão ensejada nesse conjunto de estudos que se pode remeter seu objetivo.

\section{INTERAÇÃO EM SALA DE AULA E TRABALHO DOCENTE: UMA DUPLA PERTI- NÊNCIA TEÓRICA}

Do ponto de vista teórico, o objetivo deste estudo de investigar a articulação entre a materialidade discursiva e o funcionamento didático da interação na sala de aula de alfabetização exige convocar contribuição relativa tanto ao problema da interação em sala de aula, quanto à natureza particularmente didática dessa interação,

\footnotetext{
1 Neste estudo, materialidade discursiva remete a aspectos relativos tanto ao nível textual quanto ao plano semântico-pragmático da linguagem (em interação).
} 
mais especificamente ao lugar do trabalho docente na conformação dessa última. O conjunto de aportes teóricos expostos a seguir guarda essa dupla pertinência teórica.

\subsection{Sobre a interação em sala de aula}

A abordagem da interação em sala de aula supõe, conforme uma perspectiva identificada àquela assumida por Mondada (1995), uma descrição qualitativa do contexto da sala de aula que busca "observar o modo com que os processos que se manifestam na sala de aula se constroem em práticas situadas" (p. 57). Tais processos, concebidos como processos de aquisição, de escolarização e de socialização, constituem-se nas práticas escolares de circulação de saberes e de construção de maneiras de agir (competências) e maneiras de ser (identidades).

A caracterização desses três processos proposta por Mondada reencontra a percepção de Mehan (1979) quanto à necessidade de uma "etnografia constitutiva" baseada na premissa de que as respostas para a questão do papel da escolarização na sociedade não vêm de comparações quantitativas entre escolas, mas do exame dos processos vivos de educação que ocorrem dentro de sala de aula.

$\mathrm{O}$ autor afirma que as pesquisas tendem a privilegiar muito os inputs, os dispositivos de entrada na escola, e como os alunos saem depois desse contato, o que ele chama de outputs. Assim, salienta que a escola poderia ser considerada uma espécie de "caixa preta" fixada entre os inputs e outputs da escolarização, ou seja, o que acontece no interior da escola, nas salas de aula, nas situações de avaliação, nos intervalos, nos refeitórios, na sala dos professores, na base da prática cotidiana não tem sido examinado pelos pesquisadores que discutem a influência das escolas nas sociedades.

Com o intuito de caracterizar a organização da interação entre professor e aluno, Mehan (1979, p. 36) descreve a estrutura das atividades (lessons) em sala de aula conforme três componentes: abertura, condução (instructional) e finalização. As características de cada uma dessas fases da aula são perceptíveis pela observação dos comportamentos verbais e não verbais de seus participantes materializados nas sequências interacionais, estruturas que permitem e ao mesmo tempo constituem os eventos em sala de aula.

Entre as sequências interacionais frequentes no discurso do professor encontram-se as sequências de caráter diretivo, informativo e elicitativo. Os dados de que se ocupa o autor mostram que sequências de caráter mais diretivo e informativo geralmente compõem os momentos de abertura e encerramento de aulas, enquanto 
sequências elicitativas, que têm como objetivo extrair uma informação específica do interlocutor são mais frequentes durante a condução da aula pela professora, em que ocorrem as trocas orientadas para tópicos teóricos, o que muitas vezes consideramos como a substância da aula de fato.

Quando inicia uma sequência elicitativa, o professor intencionalmente busca uma espécie de simetria entre seu ato de iniciação e a resposta do(s) aluno(s). A simetria só estará completa quando o professor conseguir extrair de um determinado aluno ou do grupo a resposta esperada. Feito isso, a sequência interativa é concluída. Para alcançar essa simetria, dois padrões interacionais são bastante frequentes em sala de aula e ocorrem conforme os alunos reagem às iniciações da professora.

O primeiro deles ocorre quando a resposta exigida pelo ato de iniciação aparece no próximo turno de fala: o resultado é uma sequência em três partes entre professor e aluno. A primeira parte da sequência é um ato de iniciação, a segunda parte é uma resposta e a terceira é uma avaliação, funcionamento conhecido como padrão IRA. O segundo padrão é verificado quando a resposta exigida pela iniciação não aparece no turno de fala seguinte. Nesse caso, o enunciador usa várias estratégias, como a repetição ou reformulação da sequência, até que a resposta com a informação esperada apareça. O resultado é uma sequência estendida de interação (MEHAN, op. cit., p. 55).

A caracterização proposta por Mehan constitui-se em aporte importante para a compreensão da dimensão interacional do trabalho docente. No contexto de sala de aula, entretanto, essa interação tem uma natureza didática constitutiva, ou seja, opera-se pela mediação do trabalho de ensino, como veremos na seção a seguir.

\subsection{Sobre a natureza didática da interação em sala de aula}

A abordagem da natureza didática da interação em sala de aula supõe considerar o lugar central do trabalho docente no processo de circulação de objetos de saber na sala de aula. Para Schneuwly (2009), é pela mediação do trabalho docente que tais objetos, uma vez previstos como objetos de ensino nos programas e currículos, transformam-se, nas práticas de ensino efetivas, em objeto ensinado. Assim, o objeto ensinado é "o resultado constantemente retrabalhado da ação do professor, que segue uma lógica própria, articulado continuamente a outra ação, à aprendizagem escolar, que, por sua vez, segue a lógica dos alunos" (SCHNEUWLY, 2009, p. 24).

Dois gestos fundadores do trabalho docente dão corpo a esse processo de mediação em que objetos de ensino se reconfiguram como objetos ensinados na interação em sala de aula: por um lado, os objetos de ensino são tornados pre- 
sentes (presentificados) na cena didática "por diferentes procedimentos de ensino (objetos, textos, fichas, exercícios, situações-problema etc.)"; tornam-se, portanto, objetos de uso, de consumo, "a propósito do qual novas significações podem e devem ser elaboradas" (SCHNEUWLY 2009, p. 31). Por outro lado e em relação de reciprocidade com o gesto de presentificação, os objetos são topicalizados, ou seja, determinadas dimensões ou aspectos deles constitutivos são eleitos como pontos ou tópicos a serem tratados como objetos de estudo particulares. Em síntese, para que os objetos de ensino sejam alçados à condição de objetos ensinados, eles passam por dois processos complementares de semiotização (SCHNEUWLY, 2009): a presentificação e a topicalização.

No processo de construção do objeto ensinado, o trabalho docente atua pelo uso de instrumentos didáticos, um conjunto complexo de dispositivos que permite a instanciação do contexto de ensino e a criação das condições de ingresso do aluno na atividade escolar proposta. Concebidos no seio das disciplinas escolares ou áreas de conhecimento, os instrumentos didáticos compreendem tanto recursos de ordem material (o conjunto do material escolar: livros didáticos, registros em áudio e vídeo, cadernos de exercícios, apostilas, textos xerocopiados etc.), quanto de ordem discursiva (o conjunto de discursos institucionais sobre o objeto de saber e sobre o modus operandi de seu ensino). Incorporados historicamente às práticas escolares, esses instrumentos são remodelados continuamente na sala de aula durante os processos interacionais, ao mesmo tempo em que ajudam a remodelar as interações do professor com os alunos e dos alunos entre si, em uma relação de reciprocidade constitutiva.

\section{CONTEXTO, CORPUS E UNIDADES DE ANÁLISE}

As próximas subseções apresentam a descrição do contexto em que se processou a pesquisa, bem como do corpus gerado e das unidades que subsidiam sua descrição e análise.

\subsection{A escola, a professora e a turma}

A escola na qual se realizou o estudo pertence à rede de ensino municipal de Taboão da Serra, cidade da região metropolitana de São Paulo, estando localizada próximo ao centro do município e contígua à zona oeste da metrópole paulistana. Na ocasião da pesquisa de campo, a escola não destoava do perfil geral da rede de ensino, contando com aproximadamente 1.200 alunos matriculados no 
Ensino Fundamental, distribuídos em três turnos, e com dez salas de aula. A média de alunos por turma era de aproximadamente 35 alunos. $O$ período diário de permanência dos alunos na escola iniciava às $7 \mathrm{~h} 10 \mathrm{~min}$ e terminava às $11 \mathrm{~h} 50 \mathrm{~min}$.

A professora, cujo trabalho foi acompanhado, estava com 32 anos de idade na ocasião da pesquisa de campo e atuava como funcionária efetiva da rede municipal há cinco anos. Esse também era seu tempo de experiência no ensino fundamental. Formada em pedagogia por uma instituição privada de ensino desde 2002, sua experiência anterior à rede municipal, além dos estágios supervisionados durante a graduação, ocorreu em turmas de berçário como professora de desenvolvimento infantil em instituições privadas. Participou também de diversos cursos de formação continuada oferecidos pela Secretaria Municipal de Educação de Taboão da Serra, em especial os que traziam debates sobre temas tais como alfabetização e letramento.

A turma acompanhada foi um 2o. ano do Ensino Fundamental I que contava com 37 alunos matriculados na ocasião da pesquisa de campo. Os alunos apresentavam diferentes níveis de desenvolvimento nas diversas áreas. Especificamente no que concerne à aquisição da escrita, no início da pesquisa de campo observamos, por meio de avaliação diagnóstica² realizada pela professora, que 18 alunos já liam e escreviam convencionalmente e 19 estavam em processo de aquisição do sistema de escrita. Apesar dos diferentes estágios de alfabetização em que se encontravam os alunos, vale salientar que a escolarização de grande parte da turma foi realizada, no ano imediatamente anterior, na própria unidade escolar, e, no que concerne à Educação Infantil, puderam contar com as chamadas EMI (Escolas Municipais de Educação Infantil), o que implica identificarmos, mesmo ao início do ano letivo, algumas marcas próprias da cultura escolar já consolidadas na postura dos alunos.

\subsection{Geração dos dados e unidades de análise}

O processo de geração dos dados da pesquisa ocorreu no período de 15/03/2012 a 13/06/2012 e se configurou centralmente em acompanhamento de aulas na turma de alfabetização e por seu registro em áudio, em audiovídeo e em caderno de campo. $\mathrm{O}$ uso do termo aula remete à unidade administrativa de tempo em que se desenvolve o trabalho de ensino. Em geral, nas escolas brasileiras,

\footnotetext{
2 A avaliação diagnóstica aplicada pela professora seguiu o modelo estabelecido pela diretriz pedagógica da Secretaria de Educação comumente conhecido por sondagem. Torini $(2012$, p. 29) define a sondagem como "ditado de palavras com sílabas diversificadas, de palavras polissílabas a monossílabas, seguidas de uma frase".
} 
cada aula conta com 50 minutos de duração. No caso do Ensino Fundamental I, esse tempo varia conforme o planejamento da professora e o desempenho dos alunos. Essa flexibilidade é possibilitada por conta papel polivalente do professor (não há troca de professor de acordo com a disciplina escolar). Sendo assim, neste estudo, aula corresponde a dado intervalo de tempo do período diário de trabalho escolar. A aula considerada neste estudo é da área de língua portuguesa e ocupou o intervalo de tempo de 1 hora e 20 minutos, aproximadamente.

A eleição das unidades para a análise dos dados busca contemplar o interesse em compreender o trabalho da alfabetizadora pela articulação de duas de suas dimensões complementares mencionadas: a dimensão didática e a dimensão interacional. Do ponto de vista didático, a unidade de análise por que optamos é a atividade escolar, atividade concebida e mediada pelo professor, pressupondo determinados objetivos ou expectativas com relação ao objeto de ensino visado e na qual o aluno é convocado a se engajar. Trata-se de "uma das maneiras de encontrar o objeto, de trabalhá-lo, manipulá-lo, exercitá-lo e estudá-lo" (SCHNEUWLY, 2009, p. 34).

Schneuwly; Cordeiro; Dolz (2006, p. 82) definem a atividade escolar como:

[...] uma atividade de ensino-aprendizagem orientada para a totalidade ou para uma dimensão precisa do objeto de ensino. Ela se caracteriza fundamentalmente por uma instrução mais ou menos explícita que define um objetivo; ela instaura um meio material semiótico a priori favorável ao alcance desse objetivo; ela se realiza por retomadas eventuais da instrução e por uma série de ações e interações, principalmente sobre o suporte material, executadas pelos alunos e reguladas pelo professor, a fim de atingir o objetivo visado. As atividades escolares são, elas mesmas, frequentemente decomponíveis em diferentes fases (instrução, execução, correção, por exemplo) de níveis inferiores, podendo ser reagrupadas em níveis hierárquicos superiores que estruturam o todo da sequência de ensino.

Do ponto de vista interacional, a atividade escolar organiza-se, conforme propõe Mehan (1979), em abertura, condução e fechamento. Cada uma dessas etapas é construída por componentes verbais e não verbais que dão corpo às interações dos participantes. Para captar essas interações, o autor propõe a unidade de análise sequências interacionais (interactional sequences, MEHAN 1979, p. 36) que, tal como a atividade escolar, apresentam começo, meio e fim, ou seja, iniciam, desenvolvem e encerram determinados tópicos. O quadro (Quadro 1.) a seguir ilustra a relação de constituição recíproca das duas unidades eleitas para a análise: atividades escolares e sequências interacionais. 
Quadro 1. Unidades de análise

\begin{tabular}{|c|c|c|c|c|c|c|c|c|}
\hline \multicolumn{9}{|c|}{ AULA } \\
\hline \multicolumn{9}{|c|}{ ATIVIDADES ESCOLARES } \\
\hline \multicolumn{3}{|c|}{ Abertura } & \multicolumn{3}{|c|}{ Condução } & \multicolumn{3}{|c|}{ Fechamento } \\
\hline \multicolumn{3}{|c|}{ Sequências interacionais } & \multicolumn{3}{|c|}{ Sequências interacionais } & \multicolumn{3}{|c|}{ Sequências interacionais } \\
\hline início & $\begin{array}{l}\text { desenvolvi- } \\
\text { mento }\end{array}$ & fim & início & $\begin{array}{l}\text { desenvolvi- } \\
\text { mento }\end{array}$ & fim & início & desenvolvimento & fim \\
\hline
\end{tabular}

\section{UMA AULA DE LÍNGUA PORTUGUESA NO TRABALHO DE ALFABETIZAÇÃO}

A aula de Língua Portuguesa descrita e analisada, a seguir, foi eleita com base em três critérios: i) que nela tivessem sido desenvolvidas duas ou mais atividades, ii) que as atividades desenvolvidas tratassem de objetos de ensino diferentes, iii) que os instrumentos utilizados no trabalho com os objetos de ensino fossem também distintos. O estabelecimento desses critérios decorre de uma dupla suposição, a saber: i) os objetos e os instrumentos de ensino podem-se diversificar a depender da atividade implementada na aula e ii) diferentes objetos e instrumentos de ensino podem-se determinar reciprocamente no interior das atividades. A aula eleita ocorreu em 11 de maio de 2011. Em sua descrição e análise, foi selecionado um excerto de sequência interacional pertencente ao momento de abertura e de condução de cada uma das atividades escolares propostas. O quadro a seguir (Quadro 2.) ilustra as atividades desenvolvidas (cujos nomes foram atribuídos pela própria professora), os objetos de ensino para que se voltaram e os instrumentos didáticos empregados. 
Quadro 2. Atividades, objetos de ensino e instrumentos didáticos da aula do dia 11/05/2011

\begin{tabular}{|c|c|c|c|c|}
\hline Data & \multicolumn{3}{|c|}{ Componentes didáticos do trabalho da alfabetizadora } & Duração \\
\hline \multirow[t]{4}{*}{$11 / 05$} & Atividade escolar & Objeto de ensino & Instrumento didático & \multirow[t]{4}{*}{01.15 .00} \\
\hline & $\begin{array}{l}\text { Para que servem as } \\
\text { parlendas? }\end{array}$ & $\begin{array}{l}\text { - Função social do } \\
\text { gênero parlenda }\end{array}$ & $\begin{array}{l}\text { - Resultado de pesquisa feita } \\
\text { pelos alunos (cartaz) } \\
\text { - Lousa } \\
\text { - Instrução oral } \\
\text { - Performance oral }\end{array}$ & \\
\hline & $\begin{array}{l}\text { Leitura e } \\
\text { interpretação de } \\
\text { poema }\end{array}$ & $\begin{array}{l}\text { Leitura } \\
\text { - Sistema de escrita } \\
\text { - Aspectos do gênero } \\
\text { poema }\end{array}$ & $\begin{array}{l}\text { - Livro didático } \\
\text { - Lousa } \\
\text { - Instruções orais }\end{array}$ & \\
\hline & Ditado & $\begin{array}{l}\text { Sistema de escrita } \\
\text { - Convenções da } \\
\text { escrita }\end{array}$ & - Instruções orais & \\
\hline
\end{tabular}

\subsection{Atividade 1: Para que servem as parlendas?}

A primeira atividade da aula de língua portuguesa do dia 11 de maio é iniciada aproximadamente às 10 horas e 30 minutos após uma atividade da área de matemática e tem duração total de aproximadamente 21 minutos. Ela faz parte de um projeto didático que envolvia uma atividade desenvolvida havia dois dias (trabalho com o gênero textual parlenda). O instrumento didático empregado para presentificar o objeto de ensino, trazê-lo à cena didática, foi o cartaz com textos transcritos de parlendas que servia assim como um suporte mnemônico construído coletivamente pela turma em aula anterior. A esse instrumento está associado outro, a performance dos textos do cartaz, consistindo em cantá-lo, declamá-lo ou recitá-lo. Quanto à organização espacial dos participantes em sala de aula, a professora está em pé, próxima à lousa, e os alunos sentados em fileiras de duplas.

Nos turnos 52 até o 64 (duração de $\left.1^{\prime} 10^{\prime \prime}\right)^{3}$ podemos capturar o momento em que a professora inicia a atividade pelo uso do instrumento didático que busca direcionar a atenção dos alunos para o objeto de ensino (Quadro 3.).

3 As convenções de transcrição utilizadas tomam por referência as normas propostas em Preti (2003): ...: pausa; [ ]: sobreposição de vozes; :: : alongamento de $\operatorname{vogal}_{i}\left(\right.$ ): fala incompreensível $l_{i}(())$ : comentário do analista; /.../: corte na produção do locutor- : silabação. Foram também utilizados sinais de pontuação gráfica, especialmente ponto de interrogação (?), bem como as convenções ortográficas do português. As falas dos alunos são indicadas por A (quando se faz referência ao grupo) e por A1, A2 etc. (quando se trata de um dado aluno). A fala da professora é indicada por P. 
Quadro 3. Transcrição de abertura da Atividade: Para que servem as parlendas

\begin{tabular}{|c|c|c|}
\hline Turnos & Loc. & Transcrição \\
\hline 52 & $P$ & $\begin{array}{l}\text { Ferna:: do::. Maria Clara e Tami::ris... olha só... turmin: ha vamos olhar aqui pro } \\
\text { nosso cartaz um pouquin:: ho nas cantigas e parlendas que vocês trouxeram pra } \\
\text { gente... ho::je a gente vai conversar pra que que será que servem essas cantigas } \\
\text { e essas parlendas... olha lá... temos várias que a gente listou com a mamãe não } \\
\text { foi? }\end{array}$ \\
\hline 53 & A1 & foi... \\
\hline 54 & $\mathrm{P}$ & muitas todos conhecem não é verdade? \\
\hline 55 & A2 & $\operatorname{sim} \ldots$ \\
\hline 56 & $P$ & $\begin{array}{l}\text { então olha lá... corre cotia na casa da... ((a professora faz gestos chamando a } \\
\text { participação)) }\end{array}$ \\
\hline 57 & A & [ tia... corre cipó na casa da vó... ((cantam juntos) $)$ \\
\hline 58 & $\mathrm{P}$ & [lencinho na mão... ((cantam juntos)) \\
\hline 59 & A & [caiu no chão... moça bonita do meu coração... ((cantam juntos)) \\
\hline 60 & $P$ & $\begin{array}{l}\text { [pode jogar? po::de... ((cantam juntos })) \\
{[\text { na::::o }} \\
\text { óh... é diferente a nossa versão ehn? olha só... pra que que serve essa cantiga } \\
\text { da corre cotia? }\end{array}$ \\
\hline 61 & $\mathrm{~A} 3$ & é uma brincade::ira de ro::da... \\
\hline 62 & $\mathrm{P}$ & é uma brincade::ira de ro::da? \\
\hline 63 & A & sim... éh::. ((falam juntos $))$ \\
\hline 64 & $\mathrm{P}$ & $\begin{array}{l}\text { então é uma brincadeira... eu posso escrever aqui que corre cotia é uma } \\
\text { brincade::ira? }\end{array}$ \\
\hline 65 & A1 & brincadeira de roda... \\
\hline 66 & $\mathrm{P}$ & todo mundo conco::rda? ((a professora anota na lousa)) \\
\hline 67 & A & sim:: $(($ falam juntos $))$ \\
\hline
\end{tabular}

Do ponto de vista didático, as ações da professora buscam presentificar o objeto de ensino. O gesto de presentificação, nesse caso, materializa-se centralmente por meio de formulações verbais construídas na troca de turnos entre a professora e os alunos. Do ponto de vista interacional, o padrão interativo estabelecido pela professora é simplificado, constituindo-se em uma díade (I - R) composta pela iniciação da professora seguida da resposta do(s) aluno(s), pois a intenção inicial não é solicitar informações de cunho mais teórico dos alunos; ela pretende apenas utilizar suas falas com a intenção de direcionar a atenção ao objeto que será o foco do estudo. Nessa fase de abertura da atividade a professora e os alunos procuram informar uns aos outros que estão de fato organizados 
para desempenhar uma atividade específica, constituindo sequências informativas (MEHAN, 1979, p. 36).

O final do turno 60 marca o começo do desenvolvimento de trocas que buscam focalizar a dimensão do objeto de ensino eleita como tópico de estudo, exatamente a função social da parlenda: pra que que serve essa cantiga da corre cotia?. Nesse momento, é possível observar um padrão de interação em que a professora inicia sequências interacionais de caráter elicitativo, que buscam extrair informações específicas dos alunos para a construção do conhecimento no grupo de sala de aula.

$\mathrm{O}$ direcionamento da atenção dos alunos para essa dimensão particular do objeto de ensino vai-se aprofundando entre os turnos 72 e 102 (duração de 2’ 10”), localizados já na parte do desenvolvimento instrucional da atividade, ocasião em que a professora recorre a outra parlenda/cantiga - Hoje é domingo (Quadro 4.).

Quadro 4. Transcrição do momento instrucional da Atividade: Para que servem as parlendas?

\begin{tabular}{|c|c|c|}
\hline Turnos & Loc. & Transcrição \\
\hline 72 & $\mathrm{P}$ & ta bom... olha lá a próxima cantiga ou parlenda?... hoje é \\
\hline 73 & $\mathrm{~A}$ & domingo... \\
\hline 74 & $P$ & $\begin{array}{l}\text { pé de cachimbo... o cachimbo é de ouro bate no touro... }((\text { cantam juntos })) \ldots \text { o } \\
\text { touro é valente e bate na gente a gente é fraco cai no buraco o buraco é fundo } \\
\text { acabou-se o mundo... ((cantam juntos })) \text { olha só... e:: e::ssa hoje é domin::go é } \\
\text { pra brincar de ro:: da també::m? }\end{array}$ \\
\hline 75 & A & não... ((falam juntos)) \\
\hline 76 & $\mathrm{P}$ & não? é pra que? \\
\hline 77 & $\mathrm{~A} 3$ & é uma parlen::da... \\
\hline 78 & $\mathrm{P}$ & é uma parlen::da... e pra que que serve a parlen::da? \\
\hline 79 & A1 & pra cantar... \\
\hline 80 & $\mathrm{~A} 2$ & pra cantar... \\
\hline 81 & $\mathrm{P}$ & pra canta:::r... só pra canta::r? \\
\hline 82 & $\mathrm{~A} 3$ & não pra fazer assim...( ) \\
\hline 83 & $\mathrm{P}$ & olha lá... vamo/ vê/... o Pedro quer fala::r... fa::la Pe::dro... \\
\hline 84 & $\mathrm{~A} 3$ & ( ) é uma len::da... tipo... tipo boitatá::. \\
\hline 85 & $\mathrm{P}$ & é uma len:: da? \\
\hline 86 & A & é... ((falam juntos $))$ \\
\hline 87 & $P$ & $\begin{array}{l}\text { o Pedro acha que é uma len:: da óh... vou colocar aqui óh... ele acha que é pra } \\
\text { canta::r e também pode ser uma lenda... que ma::is? alguém acha mais alguma } \\
\text { coisa? ((a professora anota na lousa)) }\end{array}$ \\
\hline 88 & $\mathrm{P}$ & fa::la Pe::dro... \\
\hline
\end{tabular}




\begin{tabular}{|c|c|l|}
\hline 89 & A4 & tem personagem também.. \\
\hline 90 & P & tem persona::gem? quais são os persona::gens? \\
\hline 91 & A2 & [o touro \\
\hline 92 & P & o to::uro... \\
\hline 93 & A & o Saci... ((falam juntos $))$ \\
\hline 94 & P & ah... o Saci tá no hoje é domin::go? \\
\hline 95 & A & nã:: o... ((falam juntos) $)$ \\
\hline 96 & A3 & o cachimbo... \\
\hline 97 & P & ah... tem o cachim::bo... ((A professora sorri e balança a cabeça positivamente) $)$ \\
\hline 98 & A & ( ) ((falam juntos) $)$ \\
\hline 99 & P & cai no buraco... fa::la He::ctor... \\
\hline 100 & A1 & o mun::do:: \\
\hline 101 & A2 & o buraco é no mun::do... \\
\hline 102 & P & tá bom então... vamos lá Bruno... lá em cima... o que que a gente faz com essa \\
& música? ((a professora direciona o olhar e aponta novamente para o cartaz) $)$ \\
\hline
\end{tabular}

Entre os turnos 83 e 97 constituem-se duas sequências interacionais em que os alunos contribuem com respostas que não atendem às expectativas da professora. Na primeira (turnos 83 a 87), o aluno nomeia o texto em estudo como lenda. A resposta não é descartada pela professora: ela anota a sugestão do aluno na lousa, mesmo que não tenha focalizado o objeto que a professora buscava salientar naquele momento, no caso, esperava-se que a resposta do aluno fosse algo como "brincar", "cantar" ou mesmo "divertir-se", ou qualquer outra ação que remetesse à função social do texto.

Como padrão interacional, ocorre uma sequência estendida, pois a resposta dada pelo aluno não recebe a avaliação da professora imediatamente. A estrutura se reorganiza e apresenta: iniciação da professora, resposta do aluno, feedback da professora, resposta do aluno e avaliação da professora $(\mathrm{I}-\mathrm{R}-\mathrm{F}-\mathrm{R}-\mathrm{A})$. É possível considerar o turno 87 como a realização de uma avaliação por parte da professora, embora ele não tenha sido construído verbalmente como as avaliações mais comuns, do tipo muito bem!, parabéns, isso mesmo etc. Nessa direção, cabe mencionar a relevância, apontada por Mehan (1979), de considerarmos os aspectos não verbais da interação: ao anotar a contribuição do aluno na lousa a professora atribui o status de contribuição relevante naquele ponto específico da atividade, configurando a avaliação da sequência, completando a simetria almejada pela professora.

Após essa avaliação positiva, a professora encadeia uma nova iniciação, questionando se há mais algum aspecto da função social do texto que mereça ser men- 
cionado - alguém acha mais alguma coisa?. A resposta de um dos alunos desvia a atenção do aspecto em foco naquela atividade, uma vez que remete à existência de personagens no texto e não à função social do gênero (turno 89: tem personagem também). Julgando relevante essa contribuição, talvez por remeter a aspecto constitutivo do texto em estudo, a professora acolhe a contribuição e rapidamente a integra na sequência.

Entre os turnos 90 e 97, uma das respostas dos alunos às perguntas tem personagem? quais são os personagens? surpreende a professora. A essa pergunta, alguns alunos respondem Saci, nome de personagem do folclore brasileiro que não é mencionado no texto em questão. A resposta causa estranhamento à professora, levando-lhe a formular um feedback no formato de uma pergunta que busca fazer com que os alunos reformulem o turno anterior: o saci tá no boje é domingo? (turno 95); um dos alunos atende à solicitação da professora e responde o cacbimbo (turno 96). Talvez por compartilhar um universo cultural bastante próximo ao do aluno, a professora pôde compreender rapidamente a associação metonímica feita por ele. A troca interativa constrói-se, nesse caso, conforme o padrão I - Rs - F - R - A (Iniciação da professora, Respostas dos alunos, Feedback da professora, Resposta do aluno e Avaliação positiva da professora), mais uma vez, uma sequência estendida.

\subsection{Atividade 2: Leitura e interpretação de poema}

A segunda atividade desenvolvida no mesmo dia se inicia aproximadamente às $10 \mathrm{~h}$ e $55 \mathrm{~min}$ (Quadro 5.), momento em que a professora anuncia que a nova atividade de língua portuguesa vai começar e que utilizarão o livro didático. Após a entrega dos livros, a professora informa em qual página a atividade será desenvolvida:

Quadro 5. Transcrição da abertura da Atividade: Leitura e interpretação de poema

\begin{tabular}{|c|c|l|}
\hline Turnos & Loc & \multicolumn{1}{c|}{ Transcrição } \\
\hline 285 & P & $\begin{array}{l}\text { eh.:: então vamos lá... todo mundo abrindo o livro na página setenta e seis e } \\
\text { eu vou fazer a leitura... todo mundo... até quem não acabou de copiar... página } \\
\text { setenta e seis... o sete e o seis... colocou a data... dia onze do cinco... }\end{array}$ \\
\hline 286 & A3 & $\begin{array}{l}\text { óh.. gente é assim óh... ((o aluno vai até a professora e faz gesto com a mão... } \\
\text { a professora sorri...)) }\end{array}$ \\
\hline 287 & P & xiu::: ((a professora bate na mesa)) \\
\hline 288 & A1 & oh... professo::ra até quem não acabou? \\
\hline
\end{tabular}




\begin{tabular}{|c|l|l|}
\hline 289 & P & $\begin{array}{l}\text { e::u pedi pra conversar? e também não pedi pra fechar caderno... brincan:: do } \\
\text { com as palavras... len::do o texto"... vocês vão acompanhando... "uma turma } \\
\text { inesquecível" quem escreveu foi duda machado... "conheci um gato chamado } \\
\text { lencin toda vez que miava espirrava atchim::. conheci uma vaca chamada } \\
\text { quila::te dava um leite branquin::ho sabor de chocola::te /.../ então olha só na } \\
\text { primeira estrofe... tá falando do gato... então peguem a palavra gato... e liga } \\
\text { até o desenho do gato... }\end{array}$ \\
\hline
\end{tabular}

Dos turnos 285 a 289 (duração de 2' 6") identificamos o uso do livro didático como instrumento material para desencadear o desenvolvimento da Atividade 2 (Quadro 6.). O texto sobre o qual se realiza a atividade intitula-se Uma turma inesquecível e se encontra no livro didático de Língua Portuguesa adotado na turma. A esse instrumento associa-se outro, a leitura oral do texto pela professora, pelo qual ela busca presentificar o objeto de ensino nesta atividade. Feita a leitura do poema, a professora inicia uma espécie de paráfrase dos exercícios propostos no livro, tendo em vista que os alunos ainda não teriam autonomia suficiente para a realização individual da leitura desses exercícios. Introduz, por essa via, um terceiro instrumento didático - a tarefa (v. SCHNEUWLY, 2009) -, cuja formulação se dá ao final do turno 289.

Quadro 6. Transcrição do momento instrucional da Atividade: Leitura e interpretação de poema

\begin{tabular}{|c|c|c|}
\hline Turnos & Loc & Transcrição \\
\hline 289 & $P$ & $\begin{array}{l}\text { /.../ então olha só na primeira estrofe... tá falando do gato... então peguem a } \\
\text { palavra gato... e liga até o desenho do gato... }\end{array}$ \\
\hline 290 & A1 & professo::ra gato é ? ( ) \\
\hline 291 & $\mathrm{P}$ & ga... como que é o ga? \\
\hline 292 & A & $\mathrm{g}-\mathrm{a}(($ falam juntos $))$ \\
\hline 293 & $\mathrm{P}$ & g - a... é conheci um ga::to::. pega o gato e liga até o desenho do gato... \\
\hline 294 & A2 & eu já liguei profa.. \\
\hline 295 & $\mathrm{P}$ & como que é o ga? \\
\hline 296 & A & $\mathrm{g}$ - a ((falam juntos $))$ \\
\hline 297 & $P$ & e o to? \\
\hline 298 & A & $\mathrm{t}-\mathrm{o}(($ falam juntos $))$ \\
\hline 299 & $P$ & $\begin{array}{l}\text { ga - to... então olha lá óh... g - a - t - o... acharam? ((Professora se levanta e } \\
\text { escreve a palavra na lousa)) }\end{array}$ \\
\hline 300 & A3 & ( ) eu não achei pro::fa \\
\hline
\end{tabular}




\begin{tabular}{|l|l|l|}
\hline 301 & P & $\begin{array}{l}\text { só procurar... ta logo no come::ço... xi::. ai meu Deus do cé:: u... é esse que ta } \\
\text { aqui? então usa esse ... vai... na segunda estrofe ta... conheci uma vaca chamada } \\
\text { quilate... dava um leite branquinho sabor chocola::te ... a vaca ta aqui... agora } \\
\text { procura o nome da vaca aqui e põe... como que eu faço o va::? }\end{array}$ \\
\hline
\end{tabular}

Essa tarefa volta-se para o ensino de um objeto de natureza (orto) gráfica: reconhecimento de palavras que nomeiam entidades do mundo - animais, no caso em questão. Esse reconhecimento, que supõe certa memória ortográfica, considerado talvez tarefa simples pela professora tendo em vista a rapidez com que a leitura oral e a formulação da tarefa foram realizadas, esbarra, entretanto, no grau de letramento de alguns alunos que ainda não dominam a escrita convencional e, desse modo, não conseguem executar o que havia sido solicitado.

Do turno 290 até o turno 299 a troca de turnos entre alunos e professora se ocupa das letras que compõem a palavra gato. Em função das dúvidas de identificação interpostas pelos alunos, a professora lança mão de dois instrumentos didáticos complementares: escreve o nome gato na lousa (turno 308). Essa tentativa de clarificação da tarefa, contando com o auxílio de um instrumento material (a lousa e a anotação do nome) que, em princípio, não seria usado, ainda não foi suficiente para sanar as dúvidas dos alunos quanto à tarefa de identificar o nome na página indicada (turnos 300 e 301). Como último recurso, além de escrever na lousa o nome, a professora coloca o livro logo abaixo da palavra grafada com giz, reformulando pela última vez a instrução e indicando espacialmente a resposta: só procurar... tá logo no come::ço... Em seguida, prossegue com a mesma tarefa formulando nova instrução: agora procura o nome da vaca aqui e põe. Após o exercício proposto pelo livro de ligar o nome à ilustração, o roteiro de exercícios inclui leitura de pequena biografia do autor do poema, trabalho com as noções de verso, estrofe e rima e, por fim, uma tarefa em que o aluno deve relacionar ou ligar características listadas de um certo animal a seu nome.

Do ponto de vista interacional, o traço que mais distancia essa atividade da primeira é o caráter diretivo da mediação da professora. $\mathrm{O}$ uso do livro didático e o tipo de tarefa proposta (os alunos devem ligar um elemento a outro) parecem afetar a temporalidade da avaliação por parte da professora: no momento em que se dá a interação ela não consegue olhar diretamente no livro de cada aluno para conferir se o que foi feito atende às expectativas ou não, o que torna inviável a avaliação da tarefa simultaneamente à sua realização, exatamente o contrário do que ocorreu na primeira atividade, em que todos estavam centrados no mesmo suporte material e as participações recebiam sua avaliação imediatamente. O padrão interativo dominante configura-se, assim, em uma díade: iniciação da professora e resposta do aluno $(\mathrm{I}-\mathrm{R})$, adquirindo essa última um estatuto de prestação de contas materializado 
em asserções tanto afirmativas - eu já liguei (turno 294) -, quanto negativas - eu não achei (turno 300).

\subsection{Uma atividade apenas iniciada: Ditado}

A terceira atividade do dia é implementada apenas parcialmente pela professora e marca o encerramento temporal da unidade aula (o início da atividade se dá às $11 \mathrm{~h}$ e $35 \mathrm{~min}$ ), sendo que alunos e professora já se encontram, visivelmente, bastante desgastados (Quadro 7.). Podemos observar como a instanciação da atividade, um ditado, por meio da formulação de instruções para a realização da tarefa, constitui-se em relação de imbricação com gestos de outra natureza, relacionados a questões de ordem disciplinar e burocrática, determinados por processos institucionais que, embora afetem diretamente o trabalho docente, tem suas forças motrizes localizadas para além dele. Assim, a maneira com que a professora organiza essa última atividade do dia desvela aspectos que ultrapassam a dimensão especificamente didática do trabalho docente (aquela relacionada, como vimos, aos objetos de ensino visados e aos os instrumentos de ensino empregados), mas que nem por isso são menos intervenientes na configuração da interação em sala de aula, podendo-se converter em dados relevantes para sua interpretação.

Quadro 7. Transcrição da abertura da Atividade: Ditado

\begin{tabular}{|c|c|c|}
\hline Turnos & Loc. & Transcrição \\
\hline 634 & $\mathrm{P}$ & $\begin{array}{l}\text { aí o lucas vai recolher o livro da fileira... o maicol da fileira... o joão vitor... o } \\
\text { pedro... a bianca... e o fe::lipe... e vai por aqui no balcão... e aí pega o caderno } \\
\text { de português que nós vamos fazer um ditado... }\end{array}$ \\
\hline 635 & $\mathrm{~A} 1$ & dita::do? \\
\hline 636 & A & eh::.. ( ) ((falam juntos $))$ \\
\hline 637 & $\mathrm{P}$ & $\begin{array}{l}\text { pode sentar... no::ssa... desse jeito mesmo... parabéns... olha o silêncio que } \\
\text { delí::cia... só por no balcão e sentar... } \\
\text { ((palmas)) e pegou o caderno e escreve lá... depois que pintou a linha... } \\
\text { dita:: do... }\end{array}$ \\
\hline 638 & $\mathrm{~A}$ & ditado... ditado... \\
\hline 639 & $\mathrm{P}$ & $\begin{array}{l}\text { eu não falei pra falar... eu falei pra escrever... mas... mas eu não acredito viu... } \\
\text { o que eu passo na lousa não é pra fazer? }\end{array}$ \\
\hline 640 & A & é... \\
\hline 641 & $\mathrm{P}$ & $\begin{array}{l}\text { ué... então o porquê da pergun::ta? eh::. conver::sa...vi::u...põe no balcão... } \\
\text { para de batu::que... Fernando você já acabou? olha a conver::sa que está:: na } \\
\text { sa::la... e eu não terminei lição nenhu::ma... vamo/ Heloi::sa... }\end{array}$ \\
\hline
\end{tabular}




\begin{tabular}{|c|c|c|}
\hline 642 & A & professora... posso conversar baixinho? \\
\hline 643 & $\mathrm{P}$ & você já acabou e ele também? bem:: baixin::ho... \\
\hline 644 & A & $\begin{array}{l}\text { ( ) ((Uma aluna se dirige a mesa da professora com o livro em mãos e } \\
\text { aparentemente faz uma pergunta)) }\end{array}$ \\
\hline 645 & $P$ & o que que você acha... \\
\hline 646 & A & ( ) \\
\hline 647 & & $\begin{array}{l}\text { não precisa vim até aqui me perguntar... o combinado foi bem baixinho... } \\
\text { maicol e... e lucas... pega a agenda que tem recado... e abre no dia de hoje... } \\
\text { onze... quem já acabou pega a agenda e abre no dia de hoje... que eu vou } \\
\text { chamando... abre no dia de hoje... o maicol e o lucas já traz... traz a cola } \\
\text { também /.../ ((movimentação geral dos alunos para pegar a agenda conforme } \\
\text { solicitado pela professora) })\end{array}$ \\
\hline 648 & $\mathrm{~A} 3$ & to levan::do... \\
\hline 649 & $P$ & $\begin{array}{l}\text { esse era de ontem... lembra que eu falei pra trazer com a lição pra colar } \\
\text { amanhã::? eh::. viu... vamo/... óh a conversa... fernando e... óh... fernando e... } \\
\text { traz a agenda...tatiana traz a agenda e a cola... xi::. }\end{array}$ \\
\hline 650 & A1 & eduardo.. \\
\hline 651 & $P$ & $\begin{array}{l}\text { eh::.: cadê a cola fernan:: do? eduar:: do traz a agen:: da... olha a conversa } \\
\text { pra poder colar o bilhete... olha o combinado... eu deixei conversar bem } \\
\text { baixinho... samuel e tiago... depois a gente fala sobre isso ta? maicol... maicol... } \\
\text { o combinado é baixo com o seu amigo do:: lado... cadê a cola? /.../ ai ai ai... } \\
\text { quem não sabe falar baixo vai abaixar a cabeça... }\end{array}$ \\
\hline
\end{tabular}

Logo nos primeiros turnos ocorre uma reorganização do espaço interacional quando a professora solicita que alguns alunos recolham os livros que estavam sendo utilizados na atividade anterior, compondo sequências diretivas, que exigem a tomada de ações procedimentais envolvendo questões materiais e espaciais (MEHAN, 1979, p.49). Em seguida, anuncia oralmente a terceira atividade do dia, ao mesmo tempo em que escreve o nome dessa última na lousa. No turno 637, ao formular a tarefa, a professora solicita que os alunos pintem a linba, procedimento recorrente no contexto alfabetizador que visa a subsidiar o aluno no domínio da técnica da escrita, pelo menos do ponto de vista de sua disposição espacial.

A partir do turno 639 é formulada uma série de comandos voltados à gestão do grupo, do tempo e do espaço escolares, e praticamente mais nada é dito a respeito da atividade. A preocupação da professora, nesse momento, gira em torno de questões como: a organização do material escolar, a finalização das atividades anteriores por alguns alunos, questões burocráticas como a comunicação entre escola e pais por meio de bilhetes que são colados um a um nas agendas dos alunos e com questões disciplinares. A atividade não se desenvolve efetivamente, configurando- 
-se, nessas condições, como uma espécie de estratégia utilizada para organizar o espaço sala de aula de modo que a professora pudesse cumprir essas outras incumbências que a escola delega ao professor e que não estão diretamente relacionadas com o andamento da atividade nem com o objeto de ensino eventualmente visado.

\section{CONSIDERAÇÕES FINAIS}

Em aproximadamente uma hora e vinte minutos de aula, a professora atuou como mediadora da interação na sala, dirigindo a atenção dos alunos a diferentes objetos de ensino. A descrição desse fluxo contínuo do cotidiano da aula de língua portuguesa permite apontar elementos teóricos para a compreensão da natureza da mediação da alfabetizadora e dos desafios do trabalho de alfabetizar.

$\mathrm{Na}$ análise da atividade Para que servem as parlendas? observamos como a professora organizou a interação da sala de aula por meio do uso de díades (I -R) que tiveram como objetivo direcionar a atenção dos alunos para o objeto central do projeto de ensino, as parlendas, e instaurar o componente desse objeto que seria topicalizado na tarefa proposta, no caso, os usos sociais desse gênero de texto. Ao enquadrar a atividade por meio de sequências informativas e pelo uso de um instrumento de ordem material acessível ao conjunto dos alunos, o cartaz, todos tinham sua atenção voltada para o mesmo suporte. Nesse modelo de organização do evento, a professora conduziu o contato dos alunos com o objeto de ensino e conseguiu acolher todas as contribuições fornecidas por eles, sem desviar o tópico do objeto em torno do qual se constituía a atividade. O excerto que expusemos evidencia o uso pela professora de estratégias, como a reformulação e a repetição das respostas dos alunos em sequências elicitativas, na tentativa de compreender o modo com que cada um estava reconfigurando o objeto que ela pretendia ensinar, em seu processo de aprendizagem. Assim, observa-se que a interação foi organizada em uma sequência estendida, escapando do típico padrão IRA, que, caso fosse utilizado, poderia se configurar em uma série de avaliações negativas e desestimularia a participação dos alunos na atividade proposta.

Já na atividade Leitura e interpretação de poema o instrumento material utilizado sai da esfera coletiva e repousa nas mãos de cada um dos alunos: a atividade é centrada no livro didático. Essa modificação nos instrumentos didáticos utilizados causou uma notável alteração no padrão de interação considerando-se que o formato de díades ( $\mathrm{I}-\mathrm{R}$ ) se manteve, não apenas no momento de abertura da atividade, mas também nos momentos em que as tarefas foram desempenhadas. A professora não é autora da atividade, ela parafraseia o que o autor do livro propõe como objetos 
a serem topicalizados com base em um poema. A não-avaliação imediata das contribuições dos alunos (quando deveriam ligar o nome a um desenho) gerou um sentimento de frustração, com relação tanto à proposta inicialmente planejada pela professora, quanto à expectativa dos alunos, que almejavam receber o feedback por parte da professora. Essa situação é evidenciada por uma visível desorganização no padrão de interação e pelo uso de um instrumento didático que não estava previsto para aquela atividade - a lousa -, acionado pela professora com o intuito de recuperar a atenção coletiva do grupo e, desse modo, resolver os entraves surgidos na realização da atividade.

$\mathrm{Na}$ terceira e última atividade iniciada nesse dia de trabalho, observamos como a professora utiliza a própria atividade como um instrumento de trabalho para poder resolver questões de ordem burocrática e disciplinar. Sequências diretivas são amplamente utilizadas de modo a reorganizar o espaço físico e material da sala de aula, e acabam por marcar o encerramento temporal da unidade aula. Conforme mencionamos, a unidade aula assume características peculiares no Ensino Fundamental I, em que o professor tem papel polivalente e acaba por nortear o andamento das atividades de acordo com o desempenho dos alunos nas tarefas propostas e não necessariamente de acordo com o tempo institucional. Assim, a (não) realização desta terceira e última atividade deveu-se, em grande parte, ao próprio desenvolvimento das duas atividades anteriores.

Essa interdependência das atividades escolares propostas, dos objetos de ensino visados, dos instrumentos didáticos utilizados e o modo com que se afetam reciprocamente produz efeitos no modo de configuração da interação entre a professora e os alunos. Apenas para ilustrar essa ordem de questão, vale confrontar as duas primeiras atividades no que tange aos instrumentos didáticos utilizados e as particularidades que estes assumem em atividades destinadas a alunos em processo de aprendizagem do sistema de escrita alfabética. Quando o objeto de ensino, na primeira atividade, exigiu a habilidade de uso de um texto e de reflexão sobre sua função social, estando os alunos e a professora orientados para um suporte material - o cartaz - comum ao grupo, suas participações tornaram-se mais sensíveis à distensão, no sentido de mais sensíveis à negociação sobre os tópicos de que ambos se ocupavam. Quando, entretanto, na segunda atividade, o objeto de ensino exigiu a habilidade de reconhecimento visual de letras e nomes e sua associação aos desenhos das entidades correspondentes, sendo o livro didático o suporte material de atuação do aluno (como recurso de sua ação de aprendizagem) e da própria professora (como instrumento de trabalho), suas participações tenderam mais à contenção, no sentido de menos sensíveis à negociação sobre os tópicos tratados. 
Ora, qualificar como mais contido ou mais distenso o formato adquirido pela interação entre professora e alunos ao longo de um período diário de aula de língua portuguesa não nos parece permitir derivar daí automaticamente a adequação ou a eficácia de determinados objetos de ensino, atividades escolares e instrumentos didáticos na garantia do engajamento dos alunos e na produção de uma certa disposição para a aprendizagem, como se adequação e eficácia estivessem per se inscritas nas propriedades dos objetos, das atividades e dos instrumentos.

Outras incursões por corpora de práticas de alfabetização podem fornecer pistas suscetíveis de elucidar aspectos centrais da natureza do trabalho de alfabetizar considerando-se diferentes contextos sociais e culturais. Nessa direção, uma questão a ser explorada refere-se à natureza do objeto de saber (a língua escrita) implicado nesse trabalho: em outras palavras, como se constituem e se articulam diferentes planos (grafo-fônico, morfossintático, semântico-pragmático) e níveis (lexical, frasal, textual) desse objeto de saber no trabalho de alfabetização. Tal questão está suposta, por exemplo, no arranjo que as atividades propostas pela alfabetizadora adquirem ao longo do período de aula descrito. $\mathrm{O}$ modo de configuração dessas atividades no tempo é uma decisão provavelmente motivada pela tentativa de contemplar diferentes dimensões da escrita como objeto de ensino ${ }^{4}$, sendo que, não raras vezes, está relacionada simplesmente com a resistência física da alfabetizadora dada, por exemplo, a exuberância do deslocamento espacial implicado na abordagem do grupo de crianças no contexto alfabetizador; uma espécie de break para que ela possa respirar e dar continuidade a seu trabalho.

Está nesse olhar atento para as práticas de alfabetização, para as ações dos indivíduos que constroem dia a dia essas práticas, um desafio importante tanto para a busca de respostas às questões de ensino e aprendizagem no desenvolvimento da pesquisa sobre interação em sala a que se refere Ângela Kleiman (1991), quanto para a agenda de discussões sobre as políticas públicas de incremento da alfabetização em nosso país.

4 Batista (2011, p. 11-12) explora essa questão ao defender que, em termos de políticas públicas para o ensino de língua no Brasil, haveria necessidade de focalizar o processo de consolidação da alfabetização, o que pode ser compreendido como a progressão da aprendizagem do alfabetizando na direção de aquisição das habilidades de leitura e produção de textos. Nas palavras do autor, "[...] Trata-se da indicação, por pesquisas que avaliam em larga escala o aprendizado dos estudantes brasileiros, de que, neste momento, um desafio central do ensino de língua materna reside na consolidação da alfabetização: nós teríamos dificuldades para, tendo levado os alunos a dominar o princípio alfabético e as principais correspondências grafo-fonêmicas (quer dizer, as principais relações que se estabelecem entre letras e sons no sistema ortográfico que utilizamos), conseguirmos levá-los a desenvolver a compreensão em leitura, assim como a capacidade de produzir textos". 


\section{REFERÊNCIAS BIBLIOGRÁFICAS}

BATISTA, A. A. G. (2011). Alfabetização, leitura e ensino de português: desafios e perspectivas curriculares. Revista Contemporânea de Educação, nº. 12, p. 9-35.

GOMES-SANTOS, S. N.; ALMEIDA, P. S. (2009). Pergunta-resposta: como o par dialógico constrói uma aula na alfabetização. Revista Brasileira de Linguística Aplicada. Belo Horizonte, MG: Associação Brasileira de Linguística Aplicada - Faculdade de Letras da Universidade Federal de Minas Gerais, Volume 9, nº. 1, p. 133-149.

KLEIMAN, A. B. (1991). Introdução e um Início: A pesquisa sobre interação e aprendizagem. Trabalhos em Linguística Aplicada, Campinas, SP: Instituto de Estudos da Linguagem, Universidade Estadual de Campinas, no ${ }^{\circ}$ 18, p. 5-14.

MATÊNCIO, M. de L. M. (2001). Estudo da língua falada e Aula de Língua Materna. Campinas: Mercado de Letras.

MEHAN, H. (1979). Learning Lessons: social organization in the classroom. Cambridge, MA: Harvard University Press.

MONDADA, L. (1995). Analyser les interactions en classe: quelques enjeux théoriques et reperes méthodologiques. TRANEL (Travaux Neuchâtelois de Linguistique), vol. 22, p. 55-89.

PRETI, D. (2003). Análise de textos orais, $6{ }^{a}$ Ed. São Paulo: Humanitas.

ROJO, R. H. R. (2007). Práticas de ensino em língua materna: Interação em sala de aula ou aula como cadeia enunciativa? In: Kleiman, A.; Cavalcante, A. (orgs.). Linguística Aplicada: suas faces e interfaces. Campinas, SP: Mercado de Letras, p. 339-360.

SCHNEUWLY, B. (2009). Le travail enseignant. In: Schneuwly, B.; Dolz, J. (orgs). Des objets enseignés en classe de français - Le travail de l'enseignant sur la rédaction de texts argumentatifs et sur la subordonnée relative. Rennes, FR: Presses Universitaires de Rennes, p. 29-43.

SCHNEUWLY, B.; CORDEIRO, G. S.; DOLZ, J. (2006). A la recherche de l'objet enseigné: une démarche multifocale. Les dossiers des sciences de l'éducation, vol. 14, p. 77-93.

TORINI, N. A. B. (2012). O gesto didático de regulação da aprendizagem: a sondagem em uma turma de alfabetização. Dissertação (Mestrado em Educação). São Paulo: Universidade de São Paulo, Faculdade de Educação.

Recebido: 26/06/2013

Aceito: 07/04/2014 